\title{
A PROOF OF TWO CONJECTURES OF CHAO-PING CHEN FOR INVERSE TRIGONOMETRIC FUNCTIONS
}

\author{
BRANKo MALEŠEVIĆ, BoJAN BANJAC AND IVANA JOVOVIĆ
}

Abstract. In this paper we prove two conjectures stated by Chao-Ping Chen in [Int. Trans. Spec. Funct. 23:12 (2012), 865-873], using a method for proving inequalities of mixed trigonometric polynomial functions.

Mathematics subject classification (2010): 26D05.

Keywords and phrases: Inequalities, inverse trigonometric functions, Taylor series.

\section{REFERENCES}

[1] C.-P. CHEN, Sharp Wilker and Huygens type inequalities for inverse trigonometric and inverse hyperbolic functions, Int. Trans. Spec. Funct. 23: 12, (2012), 865-873.

[2] C. Huy gens, Oeuvres Completes 1888-1940, Société Hollandaise des Science, Haga, Sweden, 1940.

[3] J. B. Wilker, Problem E 3306, Amer. Math. Monthly 96 (1989), p. 55.

[4] J. S. Sumner, A. A. Jagers, M. Vowe AND J. Anglesio, Inequalities involving trigonometric functions, Amer. Math. Monthly 98 (1991), 264-267.

[5] L. ZHU, A New Simple Proof of Wilker's Inequality, Math. Inequal. Appl. 4 (2005), 749-750.

[6] L. Zhu, On Wilker-type inequalities, Math. Inequal. Appl. 10 (2007), 727-731.

[7] L. Zhang AND L. ZHU, A new elementary proof of Wilker's inequalities, Math. Inequal. Appl. 11 (2007), 149-151.

[8] E. Neuman And J. SÁNDOR, On some inequalities involving trigonometric and hyperbolic functions with emphasis on the Cusa-Huygens, Wilker, and Huygens inequalities, Math. Inequal. Appl. 13 (2010), 715-723.

[9] C. MorTiCI, The natural approach of Wilker-Cusa-Huygens inequalities, Math. Inequal. Appl. 14 (2011), 535-541.

[10] Z.-J. Sun And L. Zhu, Some Refinements of Inequalities for Circular Functions, J. Appl. Math. 2011, Article ID 869261., 9 pp.

[11] Z.-J. Sun AND L. Zhu, On New Wilker-Type Inequalities, ISRN Math. Anal. 2011, Article ID 681702., $7 \mathrm{pp}$.

[12] C.-P. Chen AND W.-S. Cheung, Wilker- and Huygens-type inequalities and solution to Oppenheim's problem, Int. Trans. Spec. Funct. 23: 5, (2012), 325-336.

[13] C.-P. Chen AND W.-S. Cheung, Sharpness of Wilker and Huygens type inequalities, J. Inequal. Appl. 2012: Art. 72 (2012), 11 pp.

[14] E. Neuman, Wilker and Huygens-type inequalities for the generalized trigonometric and for the generalized hyperbolic functions, Appl. Math. Comput. 230 (2014), 211-217.

[15] E. Neuman, Wilker and Huygens-type inequalities for Jacobian elliptic and theta functions, Int. Trans. Spec. Funct. 25: 3, (2014), 240-248.

[16] C. MorTici, A Subtly Analysis of Wilker Inequality, Appl. Math. Comput. 231 (2014), 516-520.

[17] L. Debnath, C. Mortici, L. Zhu, Refinements of Jordan-Steckin and Becker-Stark inequalities, Results Math. 67 (1), (2015), 207-215.

[18] E. Neuman, Inequalities for the generalized trigonometric, hyperbolic and Jacobian elliptic functions, J. Math. Inequal. 9 (3), (2015), 709-726.

[19] Y. NishIZAWA, Sharpening of Jordan'st ype and Shafer-Fink's type inequalities with exponential approximations, Appl. Math. Comput. 269 (2015), 146-154. 
[20] B. Malešević, M. Makragić, A Method for Proving Some Inequalities on Mixed Trigonometric Polynomial Functions, J. Math. Inequal. 10 (3) (2016), 849-876.

[21] B. BAnJAC, M. MAKRAGić, B. MALEŠEVIĆ, Some notes on a method for proving inequalities by computer, Results Math. 69 (1) (2016), 161-176.

[22] M. Nenezić, B. MALEŠEvić, C. MORTICI, Accurate approximations of some expressions involving trigonometric functions, Appl. Math. Comput. 283 (2016), 299-315.

[23] B. MalešEvić, T. Lutovac, B. Banjac, A Proof of an Open Problem of Yusuke Nishizawa, arXiv:math/1601.00083, (2016). 